\title{
Regulation of the ndh gene of Escherichia coli by integration host factor and a novel regulator, Arr
}

\author{
Jeffrey Green, Muna F. Anjum and John R. Guest \\ Author for correspondence: Jeffrey Green. Tel: +44 1142224403 ; Fax: +44 1142728697. \\ e-mail: jeff.green@sheffield.ac.uk
}

Department of Molecular Biology \& Biotechnology, University of Sheffield, Firth Court, Western Bank, Sheffield S10 2TN, UK

\begin{abstract}
The ndh gene of Escherichia coli encodes the non-proton-translocating NADH dehydrogenase II. Expression of the nolh gene is subject to a complex network of regulatory controls at the transcriptional level. Under anaerobic conditions $n d h$ is repressed by the regulator of fumarate and nitrate reduction (FNR). However, in the absence of FNR, ndh expression is activated by the amino acid response regulator (Arr) during anaerobic growth in rich medium. Expression of the ndh gene varies during the growth cycle in response to the intracellular concentration of the heat-stable DNA-binding protein, Fis. In this work two additional heat-stable proteins, integration host factor (IHF) and the histonelike protein HU were found to interact with the ndh promoter. IHF was shown to bind at three sites centred at $+26,-17$ and -58 in the ndh promoter $\left(K_{d}=\right.$ $10^{-8} \mathrm{M}$ ), to prevent open-complex formation and to repress $\mathrm{ndh}$ transcription in vitro. Studies with an ndh-lacz fusion confirmed that IHF represses ndh expression in vivo. Two putative binding sites for Arr, which overlap the two FNR boxes in the ndh promoter, were identified. Studies with the FNRactivated and amino-acid-inducible asparaginase II gene (ansB) showed that IHF and a component of the Arr-containing fraction (but not HU) interact with the corresponding ansB promoter.
\end{abstract}

Keywords: Escherichia coli, ndh, IHF, amino acids, transcription regulation

\section{INTRODUCTION}

The facultative anaerobe Escherichia coli has two genetically distinct NADH dehydrogenases serving as primary dehydrogenases in the aerobic respiratory chain (Calhoun \& Gennis, 1993). The nuoA-N operon encodes NADH dehydrogenase I (NdhI), a membraneassociated, multi-subunit, proton-translocating enzyme, similar to complex I of eukaryotic mitochondria (Weidner et al., 1992). The ndh gene encodes NADH dehydrogenase II (NdhII) which is a membrane-bound but non-proton-translocating monomeric flavoprotein (Young et al., 1981; Matsushita et al., 1987). Significant electron flow is directed through both enzymes during glucose-limited aerobic growth (Calhoun et al., 1993) and recently it has been shown that NdhII is the

Abbreviations: Arr, amino acid response regulator; Fis, factor for inversion stimulation; FNR, regulator of fumarate and nitrate reduction; IHF, integration host factor; NbpB (NbpC), heat-stable fraction 1 (2); Ndhl (NdhII), NADH dehydrogenase I (II). preferred NADH dehydrogenase of aerobic and nitrate respiration, whereas NdhI is used during fumarate respiration (Tran et al., 1997). Because the $K_{\mathrm{m}}$ for NADH of NdhII is high (Hayashi et al., 1989) it has also been suggested that NdhII may operate to regulate the $\mathrm{NADH}$ pool independently of energy generation and is thus likely to be important when the cell's capacity to generate energy exceeds demand (Calhoun et al., 1993; Green \& Guest, 1994; Neijssel \& de Mattos, 1994).

Both NADH dehydrogenases are controlled at the transcriptional level by complex regulatory networks, reflecting their importance in aerobic and anaerobic energy generation. Expression of the nuo $A-N$ operon responds to oxygen and nitrate via ArcA (anaerobic repression) and NarL (anaerobic activation) and to $\mathrm{C}_{4}$ dicarboxylates via an uncharacterized regulator acting at a far upstream site, between -277 and -899 (Bongaerts et al., 1995). FNR (regulator of fumarate and nitrate reduction) and IHF (integration host factor) act as weak anaerobic repressors of the nuoA-N operon (Bongaerts et al., 1995), although the effect of FNR 


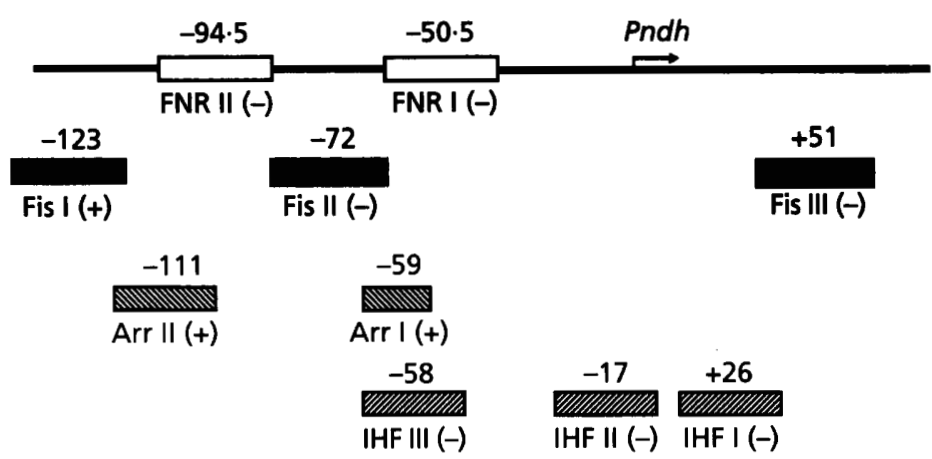

\begin{abstract}
Fig. 1. Schematic organization of the ndh promoter region of $E$. coli. The positions of regulator-binding sites are shown with centre co-ordinates relative to the transcription start point (Pndh): FNR (Sharrocks et al., 1991) and Fis (Green et al., 1996), identified previously; and the newly recognized IHF- and Arr-binding sites. The effects on ndh expression of regulator binding at each site are also indicated: positive $(+)$ or negative $(-)$.
\end{abstract}

might be a secondary consequence of its role in regulating ArcA expression (Compan \& Touati, 1994). The $n d b$ gene is subject to FNR-mediated anaerobic repression (Spiro et al., 1989) by the direct interaction of FNR with two sites in the $n d h$ promoter, FNR I and FNR II (Fig. 1; Green \& Guest, 1994). The $n d h$ gene is not regulated by ArcA but expression is activated by a novel regulator, Arr, which responds to the presence of amino acids during anaerobic growth (Green \& Guest, 1994).

As well as responding to anaerobiosis and nutrient quality, the $n d h$ promoter is subject to growth-phasedependent regulation mediated by the heat-stable DNAbinding protein Fis (factor for inversion stimulation) (Fig. 1; Green et al., 1996). At high concentrations (i.e. during early-exponential phase) Fis represses $n d h$ transcription by binding to at least three sites in the $n d b$ promoter (Fig. 1), whereas at low concentrations Fis activates $n d h$ expression by binding solely to the far upstream high-affinity site (Green et al., 1996). This paper reports the identification of two additional heatstable proteins, IHF and the histone-like protein HU, which interact with the $n d h$ promoter. IHF represses $n d h$ expression by binding to three sites in the $n d b$ promoter. In addition, two putative Arr-binding sites were identified in the $n d h$ promoter, and an Arrcontaining fraction was shown to interact with the promoter of the amino-acid-responsive asparaginase II gene (ans B).

\section{METHODS}

Bacteria and plasmids. E. coli RJ1801 (fis-985 str/spc; Ball et al., 1992) was the source of the proteins used in this study. The effects of IHF on $n d b$ expression were monitored using

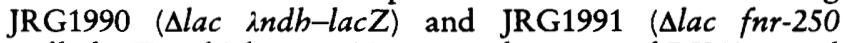
$\lambda$ ndh-lacZ), which are $\lambda \mathrm{G} 211$ monolysogens of RK4353 and RK5279 (Spiro et al., 1989), respectively, and two derivatives,

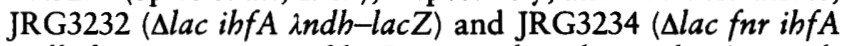
$\lambda n d h-l a c Z)$, constructed by $\mathrm{P} 1 v i r$-mediated transduction with a donor strain containing the ihfA $\Delta 82$ tet $^{\mathrm{R}}$ mutation (Schröder et al., 1993) provided by Dr R. P. Gunsalus (University of California, Los Angeles, CA, USA). Other strains of E. coli used were: JRG3229 ( $\Delta l a c$ fnr-250 $\Delta c r a:: k a n^{\mathbf{R}}$ ) derived from RK5279 by transduction with a $\Delta c r a:$ kan $^{\mathrm{R}}$ (Park et al., 1995) donor provided by Dr R. P. Gunsalus, and JRG3235, a $\lambda$ G211 monolysogen of JRG3229; JRG3314 (slac ihfA fis::neo ${ }^{\mathrm{R}}$ $\lambda n d h-l a c Z)$, a transductant of JRG3232 containing the fis::767 allele of the donor RJ1802 (Johnson et al., 1988); DF221, a gap mutant derived from E. coli K10 (HfrC tonA22 d) (Charpentier \& Branlant, 1994); and JRG3628, a glyceraldehyde-3-phosphate dehydrogenase-overproducing strain (DH $5 \alpha$ containing the gap expression plasmid $\mathrm{pBS}:$ : EcogapA) (Charpentier \& Branlant, 1994). The effects on $n d h$ expression of independent substitution of two bases within Arr I were monitored using three derivatives of the low-copy-number, broad-host-range vector pRW50 (kindly provided by Professor S. J. W. Busby, University of Birmingham) in both $\mathrm{fnr}^{+}$ (RK4353) and fnr (RK5279) backgrounds. The plasmid derivatives were: pGS994, wild-type $n d h$ promoter; pGS1075, in which the $C$ at position -66 was replaced by $G$; and pGS1076, in which the $G$ at position -55 was replaced by $C$. The base substitutions were made using the Altered Sites system (Promega) and appropriate mutagenic oligonucleotides.

The source of $n d h$ promoter DNA used in gel retardation and footprinting studies was pGS418, which contains a 422 bp EcoRI-PvuII ndh promoter fragment cloned in the EcoRI and SmaI sites of pUC18 (Sharrocks et al., 1991). The ansB promoter region was released from pGS706, a pBluescript SK(-) derivative containing a 200 bp EcoRI-HindIII fragment of pJMF1.1 (Jennings \& Beacham, 1993), for gel retardation assays. Standard procedures were used for DNA isolation and manipulation (Sambrook et al., 1989).

Growth media and $\boldsymbol{\beta}$-galactosidase assay. The medium was phosphate-buffered peptone $\left(5 \mathrm{~g}\right.$ peptone $\mathrm{l}^{-1}, 5 \mathrm{~g}$ yeast extract $\mathrm{1}^{-1}, 6 \mathrm{~g} \mathrm{KH}_{2} \mathrm{PO}_{4} \mathrm{I}^{-1}$; adjusted to $\mathrm{pH} 7.0$ with $\mathrm{NaOH}$ ) supplemented with glucose $10.2 \%$ or $1 \%$ for aerobic or anaerobic cultures, respectively). Cultures were grown at $37^{\circ} \mathrm{C}$, aerobically with vigorous shaking in conical flasks, or anaerobically in screw-cap or 'Suba-seal' bottles filled to the neck (culture surfaces were flushed with nitrogen whilst removing samples by syringe). Growth was monitored by measurement of $\mathrm{OD}_{600}$ (Pharmacia-LKB Ultrospec II). Expression of $n d h-$ lac $Z$ was monitored by assaying $\beta$-galactosidase specific activities according to Miller (1972).

Protein purification and materials. Proteins interacting with $n d h$ DNA were partially purified from clarified French press extracts of anaerobically grown RJ1801 by fractionation on heparin agarose. Extract ( $220 \mathrm{mg}$ protein) was applied to a column $(15 \times 250 \mathrm{~mm})$ of heparin agarose equilibrated with buffer A (25 mM Tris/ $\mathrm{HCl}, \mathrm{pH} 6.8$ containing $1 \mathrm{mM}$ DTT, $1 \mathrm{mM}$ benzamidine and $0.1 \mathrm{mM}$ PMSF). The column was developed with a linear gradient $(320 \mathrm{ml})$ of $0-100 \%$ buffer B (buffer A containing $1 \mathrm{M} \mathrm{KCl}$ ).

$\mathrm{NbpC}$ was further purified by applying the desalted active fractions from heparin chromatography to Bio-Scale $Q(2 \mathrm{ml})$ in Buffer $A$ and eluting with a linear gradient $(20 \mathrm{ml})$ of 
$0-100 \%$ buffer B using a Bio-Logic workstation. The active fractions were desalted by dialysis and applied to Bio-Scale CHT-I $(2 \mathrm{ml})$ in $10 \mathrm{mM}$ sodium phosphate, $\mathrm{pH} 6.8$ and eluted with a linear gradient $(20 \mathrm{ml})$ of $10-500 \mathrm{mM}$ sodium phosphate, $\mathrm{pH} 6.8$. Active fractions were detected by gel retardation assays (see below) and protein was estimated by the method of Bradford (1976).

Further purification of Arr was attempted using standard procedures including anion exchange, gel filtration and hydroxyapatite chromatography, and by using biotinylated $n d h$ promoter DNA linked to streptavidin-coated Dynabeads (Dynal), and a magnetic protein purification procedure.

Western blotting was performed by standard techniques. The levels of IHF expression during the growth cycle were estimated by quantitative densitometry of Western blots and comparison to authentic IHF standards. Samples of IHF protein and antiserum were kindly supplied by Dr $\mathrm{H}$. Nash (National Institute of Mental Health, Bethesda, USA). HNS antiserum was kindly provided by Professor C. F. Higgins (University of Oxford) and HF-I antiserum was the gift of Professor A. Ishihama (National Institute of Genetics, Mishima, Japan). E. coli RNA polymerase holoenzyme (saturated with $\sigma^{70}$ ) was obtained from Pharmacia. Radioisotopes, $\left[\alpha-{ }^{32} \mathrm{P}\right] \mathrm{dGTP}$ and $\left[\alpha^{32} \mathrm{P}\right] \mathrm{dATP}\left[>3000 \mathrm{Ci} \mathrm{mmol}{ }^{-1}\right.$ $\left.\left(>111 \mathrm{TBq} \mathrm{mmol}^{-1}\right)\right]$, and $\left[\alpha^{32} \mathrm{P}\right] \mathrm{UTP}\left[>3000 \mathrm{Ci} \mathrm{mmol}{ }^{-1}\right.$ ( $>111 \mathrm{TBq} \mathrm{mmol}{ }^{-1}$ )], were obtained from Amersham. Restriction fragments containing the $n d h$ or $a n s B$ promoter regions were end-labelled for gel retardation and DNase I footprinting reactions by filling in with the Klenow fragment of DNA polymerase. The promoters used were: $n d h$, as a 422 bp EcoRI-BamHI fragment from pGS418 labelled on the non-coding strand with $\left[\alpha-{ }^{32} \mathrm{P}\right] \mathrm{dGTP}$; and ans $B$, as a $226 \mathrm{bp}$ EcoRI-HindIII fragment from pGS706 labelled on the coding strand with $\left[\alpha^{32} \mathrm{P}\right] \mathrm{dATP}$.

Gel retardation assays. Fractions interacting with $n d h$ DNA were detected by gel retardation using end-labelled $n d h$ promoter and vector fragments, in Tris/glycine-buffered (25 mM Tris/ $\mathrm{HCl}, 190 \mathrm{mM}$ glycine, $\mathrm{pH} 8 \cdot 3$ ) $5 \%$ polyacrylamide gels. Complexes were formed at $25^{\circ} \mathrm{C}$ over $10 \mathrm{~min}$ and detected autoradiographically after gel electrophoresis at $20 \mathrm{~mA}$ constant current. The reaction mixtures, modified from Green \& Guest (1994), contained: fractions containing Arr, NbpB, NbpC or authentic IHF; 10 ng $n d b$ DNA (or ansB promoter DNA); $1 \mu \mathrm{g}$ poly(dI-dC).poly(dI-dC); $20 \mathrm{mM}$ Tris / $\mathrm{HCl}, \mathrm{pH} 8.0 ; 10 \mathrm{mM} \mathrm{MgCl}$; 0.1 mM EDTA; $60 \mathrm{mM} \mathrm{KCl}$; $5 \%(\mathrm{v} / \mathrm{v})$ glycerol; and $2 \mathrm{mM}$ DTT. The concentration of labelled promoter DNA was determined by comparison with standards on ethidium-bromide-stained agarose gels. The effect of the addition of antisera against IHF and the histonelike proteins HF-I and HNS was tested by incubating $\mathrm{NbpB}$ and $\mathrm{NbpC}$ with DNA at $25^{\circ} \mathrm{C}$ for $10 \mathrm{~min}$ prior to the addition of antisera. Incubation was continued for a further $5 \mathrm{~min}$ before electrophoretic separation of the complexes. To assess the effects of IHF on RNA polymerase binding to the $n d b$ promoter, the reactions contained combinations of IHF $(0-$ $1 \mu \mathrm{M})$ and RNA polymerase $(2-4 \mathrm{U})$ incubated simultaneously with $n d h$ promoter DNA at $37^{\circ} \mathrm{C}$ for $10 \mathrm{~min}$. RNA polymerase $-n d h$ complexes resisting a heparin $\left(0.1 \mathrm{mg} \mathrm{ml}^{-1}\right)$ challenge were fractionated on $3.9 \%$ polyacrylamide $/ 0.08 \%$ bis-acrylamide gels buffered with Tris/borate/EDTA.

Footprinting studies. DNase I footprinting reactions contained purified IHF or HU (or partially purified Arr) and $n d h$ promoter DNA. IHF $(0-10 \mu \mathrm{M})$, HU $(0-100 \mu \mathrm{M})$ or Arrcontaining fraction ( $13 \mu \mathrm{g}$ protein) were incubated for $10 \mathrm{~min}$ at $25^{\circ} \mathrm{C}$ in a total volume of $10 \mu \mathrm{l}$ with promoter DNA
(10-100 $\mathrm{ng}), 2 \mu \mathrm{l} 5 \times$ binding buffer $(0 \cdot 1 \mathrm{M}$ Tris $/ \mathrm{HCl}, \mathrm{pH} 8 \cdot 0$; $0.05 \mathrm{M} \mathrm{MgCl}_{2} ; 50 \mathrm{mM} \mathrm{DTT}$; and $25 \%$ glycerol), followed by digestion with DNase I $\left(1 \mu \mathrm{l}, 1 \mathrm{U} \mathrm{ml}^{-1}\right.$, for $60 \mathrm{sec}$ at $\left.25^{\circ} \mathrm{C}\right)$. Reactions were stopped by adding $200 \mu \mathrm{l} 0.3 \mathrm{M}$ sodium acetate containing $10 \mathrm{mM}$ EDTA followed by phenol/chloroform extraction. The DNA was ethanol-precipitated and resuspended in $7 \mu$ l loading buffer $(40 \%, v / v$, formamide; $5 \mathrm{M}$ urea ; $5 \mathrm{mM} \mathrm{NaOH}$; $1 \mathrm{mMEDTA}$; $0.03 \%$, w/v, bromophenol blue; and $0.03 \%, w / v$, xylene cyanol) for electrophoretic fractionation on polyacrylamide/urea gels and autoradiographic analysis. Maxam and Gilbert $G$ tracks were used to provide a calibration.

In vitro transcription analysis. Reaction mixtures $(10 \mu \mathrm{l})$ contained: $0 \cdot 1$ pmol template DNA; $20 \mathrm{mM}$ Tris $/ \mathrm{HCl}$, pH 8.0; $10 \mathrm{mM} \mathrm{MgCl}$; 0.1 mM EDTA; $5 \%$ glycerol; $2 \mathrm{mM}$ DTT; and IHF $(0-1 \mu \mathrm{M})$ as required. After $5 \mathrm{~min}$ at $37^{\circ} \mathrm{C}$, RNA polymerase $(2 \mathrm{U})$ was added and incubation continued for $5 \mathrm{~min}$. Transcription was initiated by adding an rNTP mixture containing ATP, GTP and CTP (final concn $500 \mu \mathrm{M}$ ), UTP (final concn $50 \mu \mathrm{M}$ ) and $\left[\alpha-{ }^{32} \mathrm{P}\right] \mathrm{UTP}(4 \mu \mathrm{Ci})$ and after $5 \mathrm{~min}$ at $37^{\circ} \mathrm{C}$ terminated by extraction with phenol/ chloroform. Nucleic acids were precipitated with ethanol, washed with $70 \%$ ethanol and resuspended in $7 \mu$ l of a mixture of $95 \%$ formamide, $20 \mathrm{mM}$ EDTA, $0.05 \%$ bromophenol blue, $0.05 \%$ xylene cyanol for electrophoretic fractionation of each entire sample in an $8 \%$ polyacrylamide/urea gel and subsequent autoradiography. Autoradiographs were scanned with a Vilber-Lourmat BioProfil imaging system.

\section{RESULTS}

\section{Proteins that interact with the ndh and ansB promoters}

Attempts to understand the complexities of $n d h$ gene transcription at the molecular level have previously focused on the role of FNR and the identification of heat-labile (Arr) and heat-stable (Fis) proteins which bind to the $n d h$ promoter in vitro (Green \& Guest, 1994; Green et al., 1996). During studies on the heat-stable $n d h$-binding protein, Fis (formerly designated $\mathrm{Nbp}$ ), it became clear that other heat-stable proteins interact with the $n d h$ promoter. In order to identify and define their roles, extracts of an anaerobically grown fis mutant (RJ1801) were fractionated on heparin agarose and fractions having $n d h$-binding activity were detected by gel retardation analysis (Fig. 2a). Interpretation of the results was simplified by starting with a Fis-deficient mutant because Fis has a very high affinity for the Fis I site in the $n d b$ promoter (Green et al., 1996) and, by spreading across the elution profile, would otherwise mask some of the $n d h$-binding activities. Three retarding components were detected in the elution profile (Fig. 2a). The first, eluting in both the wash fractions $(5-7)$ and fraction $10(0.25 \mathrm{M} \mathrm{KCl})$, contained the heat-labile protein previously designated Arr (Green \& Guest, 1994, and below). Two further components eluting in fractions $21-22(0.5 \mathrm{M} \mathrm{KCl})$ and fractions $25-26(0.65 \mathrm{M}$ $\mathrm{KCl}$ ) resembled Fis (formerly $\mathrm{Nbp}$ ) in retaining activity after heating to $90^{\circ} \mathrm{C}$ for $10 \mathrm{~min}$ (Fig. 2b). They were designated $\mathrm{NbpB}$ and $\mathrm{NbpC}$, respectively. Fractions 11-15 might contain $n d h$-binding proteins that could not be detected due to the presence of nuclease activity (Fig. 2a). The smearing of the retarded bands is probably 

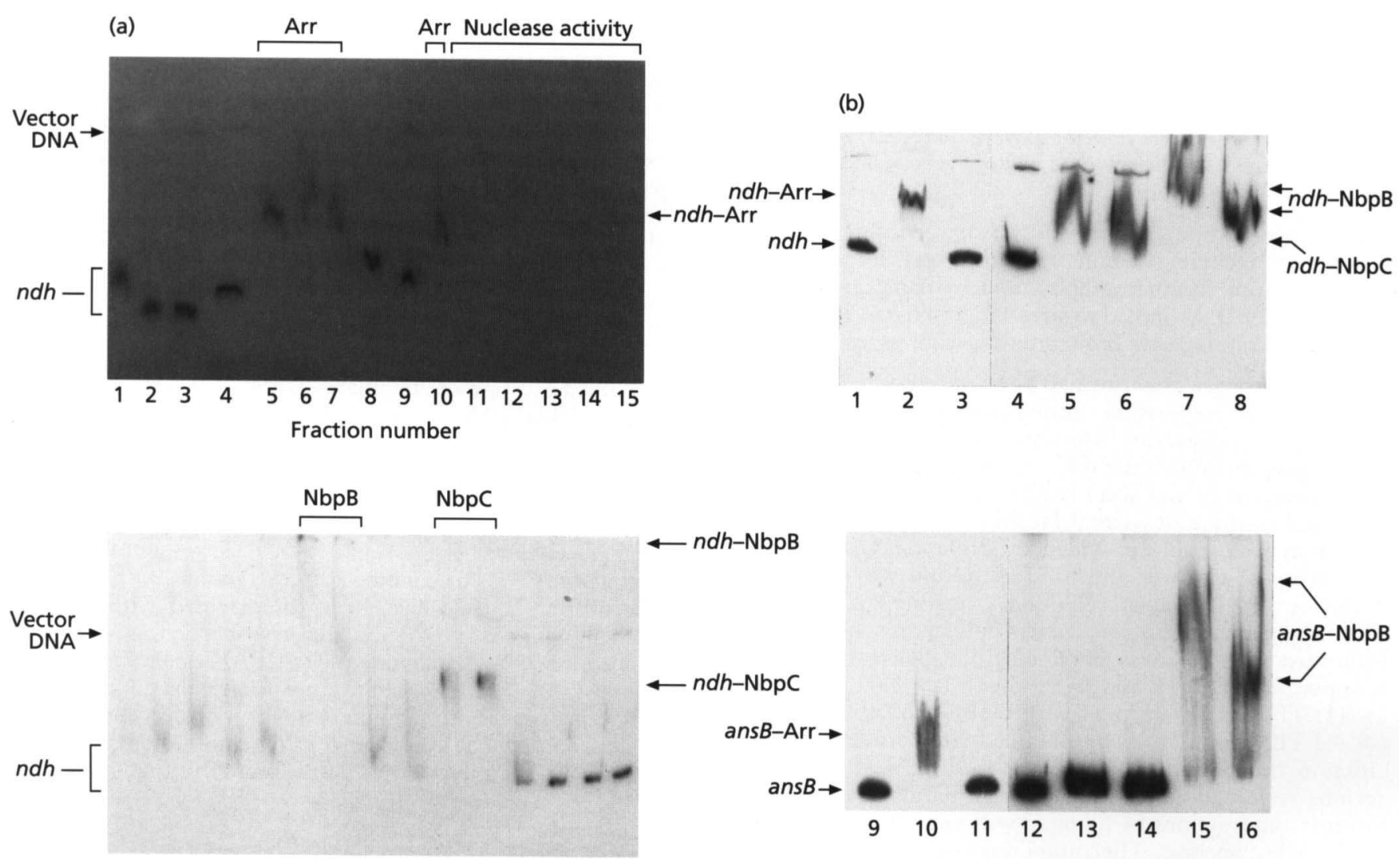

$16 \quad 171819202122 \quad 23242526 \quad 27282930$

Fraction number

Fig. 2. Detection of three ndh-binding proteins by gel retardation analysis following heparin agarose chromatography. (a) Gel retardations with fractions from heparin agarose chromatography. The positions of free ndh DNA, vector DNA, ndh-protein complexes and the fractions containing Arr, $\mathrm{NbpB}$ and $\mathrm{NbpC}$ activity are indicated. Fractions 11-15 contain a nuclease activity which digests the target DNA. (b) Gel retardation with heat-stable $n d h$ - and ansB-binding proteins. Gel retardations with ndh and ansB promoter DNA and untreated or heated fractions from heparin agarose chromatography. Lanes 1-8, ndh DNA plus: no addition (lanes 1 and 4); untreated fraction 5 (lane 2); heated fraction 5 (lane 3); fraction 25 (lane 5); heated fraction 25 (lane 6); fraction 21 (lane 7); heated fraction 21 (lane 8). Lanes 9-16, ansB DNA plus: no addition (lanes 9 and 12); fraction 5 (lane 10); heated fraction 5 (lane 11); fraction 25 (lane 13); heated fraction 25 (lane 14); fraction 21 (lane 15); heated fraction 21 (lane 16). The positions of free DNA and retarded complexes with fraction 5 (Arr), fraction $21(\mathrm{NbpB})$ and fraction $25(\mathrm{NbpC})$ are indicated.

due to residual $\mathrm{KCl}$ in the samples which makes it difficult to assess whether there is one or more retarded species in lanes 5-7 and 10 (Fig 2a); however, previous studies had indicated that Arr forms two retarded complexes with the $n d h$ promoter (Green \& Guest, 1994)

The NbpB component was identified as IHF by its immunological cross-reaction with IHF antiserum in gel retardation supershift assays (Fig. 3) and by its comigration with authentic IHF-ndh complexes (not shown). The active fractions contained two polypeptides $\left(M_{\mathrm{r}} 10000\right.$ and 9500$)$ as judged by SDS-PAGE and they were identified as IHF $\alpha$ (ALTKAEMSE) and IHF $\beta$ (MTKSELISRL) by $\mathrm{N}$-terminal amino acid sequence analysis.

The heat-stable $\mathrm{NbpC}$ protein was bound to at least two sites in the $n d b$ promoter. NbpC failed to cross-react with HNS and HF-I antisera (Fig. 3) but was identified as $\mathrm{HU}$ by $\mathrm{N}$-terminal amino acid sequence analysis (MNKTQLIDV, $\mathrm{HU} \alpha$; and MNKSQLIDK, $\mathrm{HU} \beta$ ) after purification to homogeneity as judged by SDS-PAGE. Further gel retardation studies indicated that $\mathrm{HU}$ $(\mathrm{NbpC})$ interacted with multiple sites in the $n d b$ promoter and $50 \%$ of $n d h$ DNA was retarded after incubation in the presence of $10^{-7} \mathrm{M} \mathrm{NbpC}(\mathrm{HU})$. No distinct region of protection (between -200 and +40 ) was afforded by HU in DNase I footprints, although the DNA was more resistant to digestion in the presence of $\mathrm{HU}$, which is consistent with the known properties of this protein.

Both $\mathrm{NbpB}(\mathrm{IHF})$ and $\mathrm{NbpC}(\mathrm{HU})$ retarded the vector DNA as well as the $n d h$ promoter indicating, not surprisingly, that there are binding sites for these two histone-like proteins in pUC18.

The FNR-activated ans $B$ gene of $E$. coli encodes asparaginase II and its expression is induced by the 


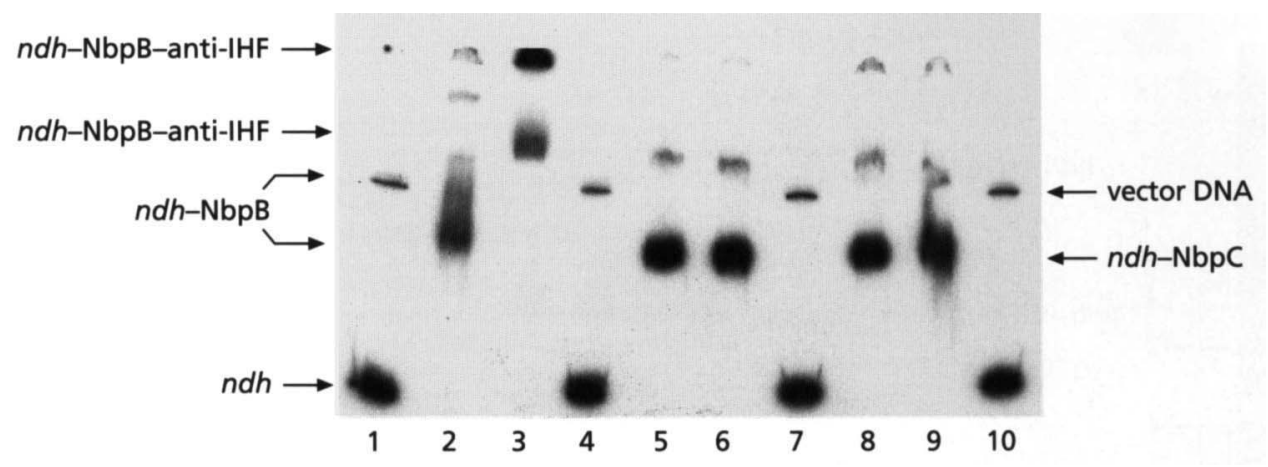

Fig. 3. Identification of $\mathrm{NbpB}$ as IHF. Gel retardation assays with end-labelled ndh promoter fragments from pGS418. $\mathrm{NbpB}$ or $\mathrm{NbpC}(14 \mu \mathrm{g}$ protein) and antisera to IHF, HNS or HF-I were used as follows: 1, no protein; $2, \mathrm{NbpB} ; 3, \mathrm{NbpB}+$ anti-IHF; 4, anti-IHF; 5, NbpC; 6, NbpC + anti-HNS; 7, anti-HNS; 8, NbpC; 9 NbpC + anti-HF-I; 10 anti-HF-I. The position of free DNA and retarded complexes are indicated.

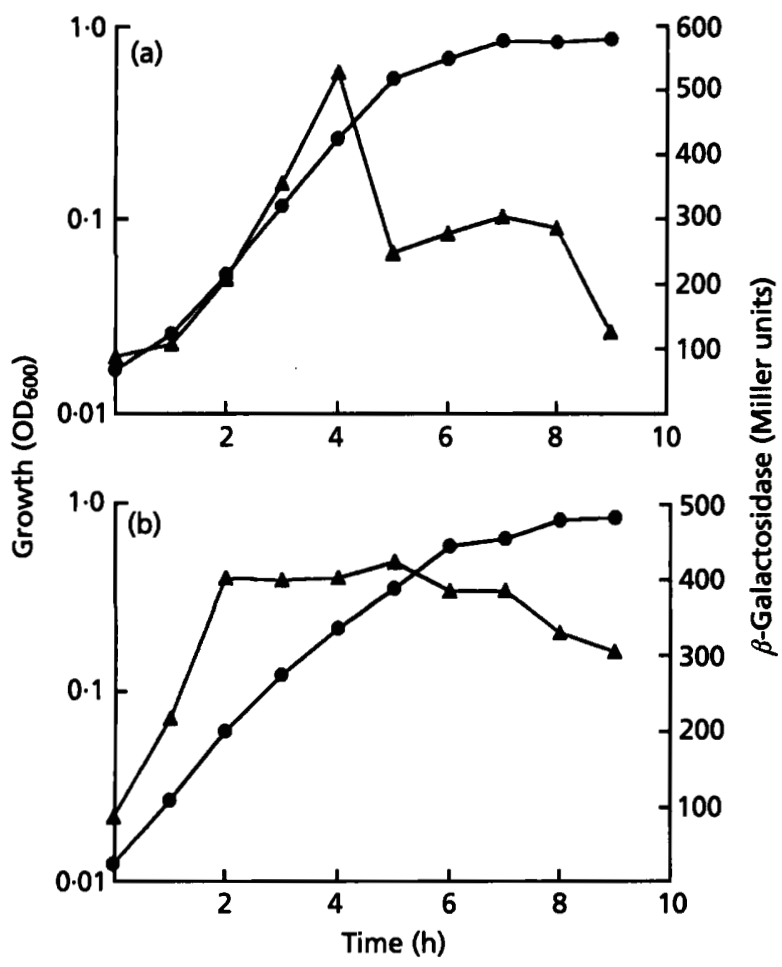

Fig. 4. Temporal expression of the ndh promoter in the anaerobic growth cycle. Anaerobic cultures of $E$. coli containing an $n d h$-lacZ reporter fusion, (a) JRG 1991 (fnr $\lambda$ ndh-lacZ) and (b) JRG3234 (fnr ihfA $\lambda$ ndh-lacZ), were sampled during the growth cycle and assayed for growth (O) and $\beta$-galactosidase specific activity (A).

presence of amino acids during anaerobic growth (Cedar \& Schwartz, 1968; Jennings \& Beacham, 1993). Gel retardation studies with the ans $B$ promoter DNA showed that Arr and IHF are bound but no interaction could be detected with HU (Fig. 2b). Similar tests with purified Fis indicated that Fis interacts with the ansB promoter (data not shown). These results are consistent with the possibility that the amino acid responsiveness of the ansB gene is mediated by Arr, as is the case for the $n d h$ gene.

\section{Repression of $\boldsymbol{n d h}$ expression by IHF}

Strains containing a $\lambda$ indh-lac $Z$ fusion prophage were used to study the effects of IHF deficiency (ihf $A$ mutation) on $n d b$ gene expression. The patterns obtained during anaerobic growth of JRG1991 $(f n r)$ and JRG3234 ( $f n r$ ibfA) are compared in Fig. 4. In the fnr mutant, expression was maximal during early- to midexponential phase but fell to about half-maximum in late-exponential phase. In contrast, expression in the double mutant increased more rapidly and was sustained at a high level into the stationary phase, indicating that IHF is acting as a repressor. The expression of $n d h$ in the ihf $A$ mutant eventually fell to the level observed in the parental strain suggesting that another regulator may partially fulfil the role of IHF in the mutant. It has been speculated that other bacterial histones such as $\mathrm{HU}$ and HNS can functionally replace IHF by virtue of their ability to bend DNA (Goosen \& van de Putte, 1995), and $\mathrm{HU}(\mathrm{NbpC})$ has indeed been shown to interact weakly with $n d h$ DNA (see above). Under aerobic conditions the overall patterns observed with both strains were similar to that observed anaerobically with the fnr ibfA $A^{+}$ strain (i.e. as in Fig 4a), except that expression was twoto threefold lower in the $f n r$ ibf $A^{+}$strain than in the $f n r$ ibf $A$ strain during mid-exponential phase, again suggesting IHF is acting as a repressor. Parallel Western blot analyses of the IHF content showed that the aerobic cultures contained approximately $1 \cdot 7$-fold more $\mathrm{IHF}$ than the anaerobic cultures, and that in both strains $n d h$ expression is low when the IHF content is high.

In comparable studies with anaerobic cultures of JRG3232 ( $\left.f n r^{+} i h f A\right), n d h$ expression was low despite the absence of IHF due to anaerobic repression by FNR. Studies with a monolysogenic ihf $A$ fis double mutant (JRG3314) showed that in the aerobic growth cycle, $n d b$ expression rises in the early-exponential phase and remains elevated into the stationary phase, not unlike 
(a)

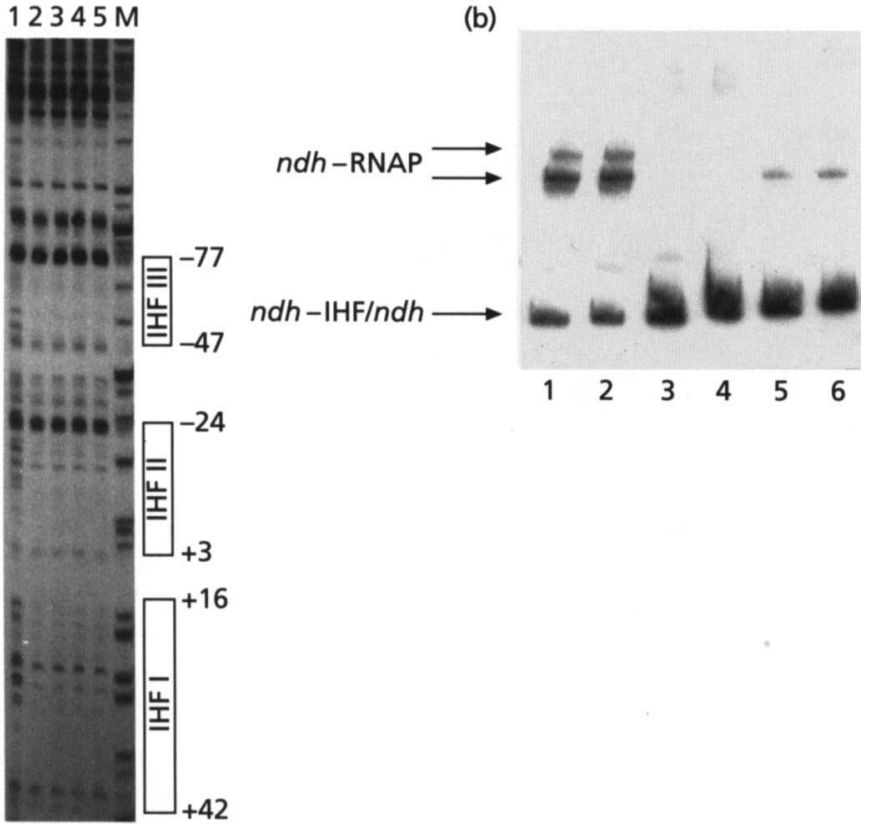

(c)

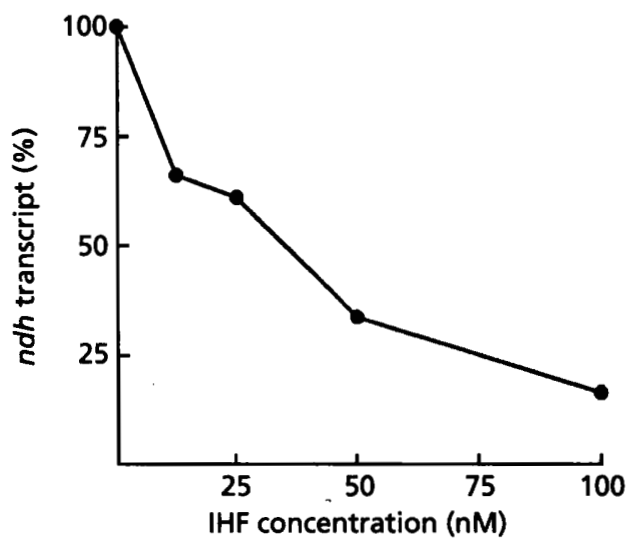

Fig. 5. Interaction of IHF with the ndh promoter in vitro. (a) DNase I footprints of the ndh promoter region labelled on the coding strand. Authentic IHF was used as follows: 1, no IHF; 2, $0.5 \mu \mathrm{M} ; 3,1.0 \mu \mathrm{M} ; 4,5.0 \mu \mathrm{M}$; $5,10 \mu \mathrm{M}$. Lane $\mathrm{M}$ shows a calibration $\mathrm{G}$ track obtained by DMS-piperidine hydrolysis of the same labelled fragment. (b) Inhibition of open complex formation by IHF. Electrophoretic separation of ndh-RNA polymerase (ndh-RNAP) complexes formed by incubation of end-labelled ndh DNA with: 1, RNA polymerase (2 U); 2, RNA polymerase (4 U); 3 , IHF $(0.5 \mu \mathrm{M}) ; 4$, IHF $(1 \mu \mathrm{M}) ; 5$, RNA polymerase (2U) and IHF $(0.5 \mu \mathrm{M}) ; 6$, RNA polymerase $(4 \mathrm{U})$ and IHF $(1 \mu \mathrm{M})$. (c) IHFmediated repression of $n d h$ transcription in vitro. Quantification of IHF-mediated repression. Production of the ndh transcript in the presence of increasing amounts of IHF was quantified by densitometry ( $\%$ of maximum). The autoradiograph shows the $n d h$ (163 nt) and ori transcripts formed in the absence $(-)$ or presence $(+)$ of IHF (100 nM). the anaerobically grown ibf A f $n r$ double mutant (Fig. $4 \mathrm{~b})$. In contrast, the aerobic expression of $n d h$ in fis mutant strains increases during early exponential phase and then falls rapidly back to the original level (Green $\boldsymbol{e t}$ al., 1996). These observations are consistent with IHF acting as both an aerobic and anaerobic repressor of $n d h$ expression.

\section{IHF represses ndh by binding to three sites in the promoter region}

Gel retardation reactions with authentic IHF indicated that IHF binds to the $n d h$ promoter with a $K_{\mathrm{d}}$ of $11.5 \mathrm{nM}\left(K_{\mathrm{d}}\right.$ is the concentration of IHF giving $50 \%$ retardation). This value is within the range observed for IHF-binding to other IHF-regulated promoters, 1-250 nM (Freundlich et al., 1992). DNase I footprinting reactions (Fig. 5a) revealed three regions of IHF protection within the $n d h$ promoter region (IHF I, +42 to +16 ; IHF II, +3 to -24 ; and IHF III, -47 to -77 ).
The protected regions are similar in size (approximately $30 \mathrm{bp}$ ) to those observed at other IHF-binding sites (Huang et al., 1990; Oppenheim et al., 1993; Resnik et al., 1996) and they contain DNA sequences (IHF I, ${ }^{+20}$ TAAcctgTTGTTA ${ }^{+32}$; IHF I, ${ }^{-23}$ CATtcatGT T ATT $^{-11}$; and IHF II, ${ }^{-64}$ ACAaaacTTGATT ${ }^{-52}$ ) which resemble the IHF consensus sequence, C/TAAnnnnTTGATA/T ( Craig \& Nash, 1984). Lower concentrations of IHF (up to $0.2 \mu \mathrm{M}$ ) resulted in equally weak protection at all three sites.

The effects of IHF on open complex formation were investigated using combinations of IHF, RNA polymerase and $n d h$ promoter DNA in gel retardation assays (Fig. 5b). Two ndh-RNA polymerase complexes were observed but only the major complex was stable to heparin challenge suggesting that the minor (slowmigrating) complex consisted of a non-specific interaction between RNA polymerase and $n d h$ DNA. The $n d b-\mathrm{IHF}$ complex was not resolved by this type of gel 


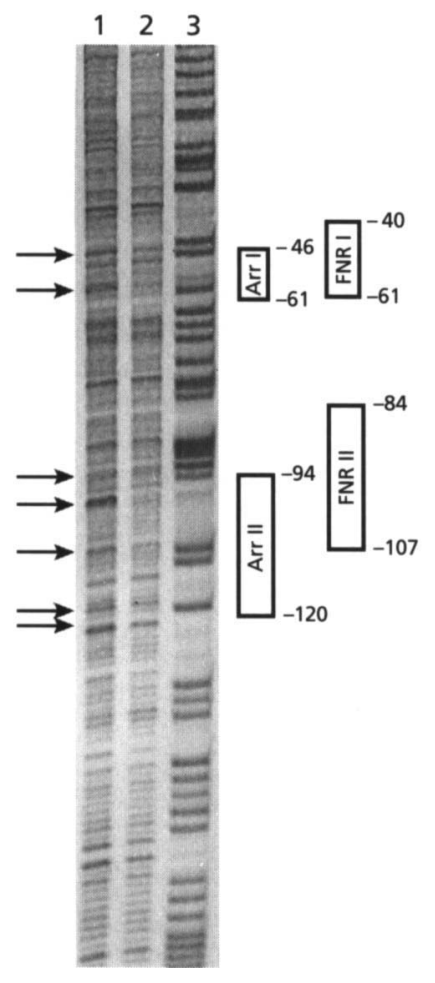

Fig. 6. Identification of Arr-binding sites. DNase I footprint of the ndh promoter region and Arr. The 424 bp EcoRI-BamHI fragment of pGS418 containing the ndh promoter, labelled on the coding strand, was used with partially purified Arr: 1, no protein; 2, Arr (13 $\mu \mathrm{g}$ protein); 3, calibrating G track. The positions of the Arr-protected bases (arrowed), and the extent of the putative Arr-binding sites and FNR sites (boxes) are indicated.

(because of the much lower bis-acrylamide content) but the presence of IHF clearly inhibits open complex formation at the $n d h$ promoter, as indicated by the release of RNA polymerase from the complex after heparin challenge. The remaining $n d h-\mathrm{RNA}$ polymerase complexes after heparin challenge represent the fraction of $n d h$ DNA unoccupied by IHF. Accordingly, increasing concentrations of IHF progressively inhibited in vitro transcription from the $n d h$ promoter whilst formation of the ori transcript was increased (Fig. 5c).

\section{Arr binds at two sites overlapping the FNR sites in the $n d h$ promoter region}

Attempts were made to characterize Arr, the novel regulator responsible for the amino-acid-responsive anaerobic stimulation of $n d h$ expression in $f n r$ mutants. A possible candidate, Cra (formerly FruR) was excluded because the anaerobic, rich-medium-dependent induction of $n d b-l a c Z$ expression was still observed with JRG3229 ( f n $\mathrm{cra}$ ). An alternative approach based on further purification of the heat-labile fractions $(5-7$ and 10) from heparin agarose chromatography (Fig. 2a) was unsuccessful due to an inherent instability of the protein.

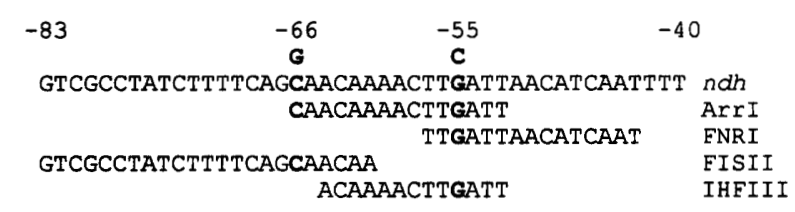

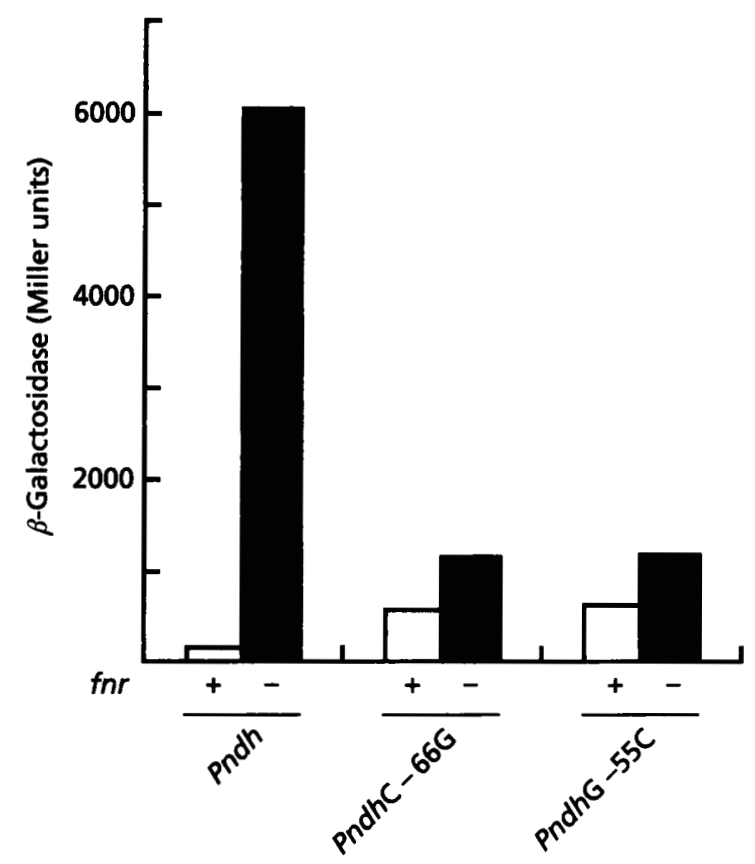

Fig. 7. Effects of Arr-l-binding site mutations on ndh expression. Two altered ndh promoters with single substitutions at positions -66 and -55 in the Arr I site were sub-cloned into the lac operon reporter plasmid, pRW50. Anaerobic $n d h$ expression driven from the altered promoters was compared to that of the wild-type ndh promoter, Pndh, by measuring the $\beta$-galactosidase activities from three pRW50 derivatives (pGS994, wild-type ndh promoter, Pndh; pGS1075, PndhC -66G; and pGS1076, PndhG -55C) in the presence (open bars) or absence (filled bars) of fnr. The nucleotide sequence (altered bases in bold) and regulator-binding sites in the relevant region of the $n d h$ promoter are shown.

Chromatography on Bio-Scale CHT-I, Mono Q and gel filtration media all resulted in loss of Arr-binding activity and attempts to rescue activity by recombining protein-containing fractions were unsuccessful. Likewise, the addition of spent medium, a potential source of co-effectors, did not improve Arr binding, nor restore activity once lost. The activity of heparin-agarosepurified Arr activity could be extended to $8 \mathrm{~d}$ by storing fractions anaerobically with DTT $(10 \mathrm{mM})$ and $\beta$ mercaptoethanol $(100 \mathrm{mM})$, compared to only $4 \mathrm{~d}$ with the untreated fraction, but Arr activity was still lost during further chromatography. Attempts to purify Arr on the basis of its DNA-binding activity using the $n d h$ promoter linked to Dynabeads produced an active fraction containing essentially pure glyceraldehyde-3phosphate dehydrogenase. However, because Arr ac- 
tivity was detected in a gap mutant, and the elution profiles of both the mutant and $\mathrm{gap}^{+}$overproducing strains on heparin agarose resembled that obtained with the wild-type (Fig. 2a) Arr is unlikely to be glyceraldehyde-3-phosphate dehydrogenase. Consequently, the partially purified material from heparin agarose chromatography provided the best source of Arr for footprinting studies. Two putative Arr-binding sites were observed (Fig. 6), Arr I ( -46 to -69 ) and Arr II $(-94$ to -120$)$, each containing related DNA sequences, ${ }^{-66}$ CAACAAAACTTGATT ${ }^{-52}$ and ${ }^{-117}$ CAATAAACTCTGTTT ${ }^{-103}$, which overlap the previously identified FNR boxes centred at -50.5 and -94.5 (Fig. 1). The same protein is also found in extracts of the fnr mutant JRG1728 and thus the observed DNA-binding activity is not due to FNR.

Site-directed substitution of single base pairs in Arr I $(C \rightarrow G$ at -66 or $G \rightarrow C$ at -55$)$ seriously reduced Arractivation of $n d h$ expression (Fig. 7). Anaerobic expression from the wild-type $n d h$ promoter in the absence of FNR was 30-fold higher than that observed in the presence of FNR. In marked contrast, the corresponding enhancements were only five-fold (relative to the wildtype) for both altered promoters in the absence of FNR, indicating that Arr-mediated activation is severely impaired. However, in the presence of FNR the altered promoters were about three-fold more active than wildtype, which may in part be due to weaker anaerobic repression by Fis, IHF and FNR, because position -66 forms part of the Fis II and IHF III sites, and the -55 substitution removes a key FNR:DNA interaction at the FNR I site (Figs 1,7). Nevertheless, the much reduced anaerobic activities observed in the absence of FNR, are consistent with inactivation of an Arr-binding site.

\section{DISCUSSION}

Transcription of the $n d h$ gene of $E$. coli is controlled by several factors responding to different stimuli. Anaerobic $n d h$ expression is repressed by FNR but enhanced in $f n r$ mutants during anaerobic growth in rich medium (Spiro et al., 1989; Green \& Guest, 1994). Expression of the $n d h$ gene also varies during the growth cycle, partially in response to Fis (Green et al., 1996).

It is now apparent that IHF also contributes to the growth-phase-dependent regulation of $n d h$. Studies with the $n d h-l a c Z$ fusion combined with Western blotting suggest that IHF represses $n d h$ expression during the late-exponential and stationary phases of growth. As a member of the RpoS regulon, the level of IHF expression increases five- to tenfold during late-exponential and stationary phases (Aviv et al., 1994; Ditto et al., 1994). Since the level of $n d b$ expression in the ihf A mutant eventually falls to the level observed in the parental strain, the role of IHF may be partially fulfilled by other bacterial histones, possibly $\mathrm{HU}(\mathrm{NbpC})$ or a homodimer of IHF $\beta$. Functional substitution of IHF by HU and HNS is not without precedent (Goosen \& van de Putte, 1995). Fis also represses $n d h$ expression in response to growth phase (Green et al., 1996) but Fis is maximally expressed during the transition between lag and exponential phases. Therefore, the amount of NdhII in the cell is controlled throughout the growth cycle by these two histone-like proteins. Fis repression occurs as a result of Fis binding to three sites in the $n d h$ promoter region. IHF occupies three regions of $n d b$ promoter DNA centred at +26 (IHF I), -17 (IHF II) and -58 (IHF III). The positions of the IHF sites are consistent with IHF acting as a repressor of $n d h$ expression; the IHF I site would block RNA polymerase progress, the IHF II site overlaps the RNA polymerase-binding site while the IHF III site overlaps the binding site of the putative anaerobic activator, Arr (see below). The IHF III site was previously predicted after analysis of the sequence of the $n d h$ promoter region and IHF-dependent retardation was observed (Green \& Guest, 1994).

IHF-binding sites have been identified in the non-coding regions of over $100 \mathrm{E}$. coli transcriptional units and IHF acts as both a positive and negative regulator (Freundlich et al., 1992; Goosen \& van de Putte, 1995). Many of the positively regulated promoters are $\sigma^{54}$-dependent and require other regulatory factors. In these cases, IHF is thought to serve as an architectural element, bending DNA to facilitate activator RNA polymerase contacts. IHF is also a positive effector of $\sigma^{70}$ promoters, some of which, for example hemA, narGHJI, narK, pfl and $\operatorname{sod} A$, are regulated in response to oxygen by FNR (Guest et al., 1996). At the pfl promoter, IHF is thought to aid the formation of a nucleoprotein complex by bending DNA to allow protein-protein contacts between ArcA, FNR and RNA polymerase (Sawers, 1993). IHF may act similarly to facilitate interaction between FNR and NarL at the narGHJI promoter (Goosen \& van de Putte, 1995). Examples of IHF acting as a repressor of $E$. coli $\sigma^{70}$ promoters without the involvement of additional regulators include $\operatorname{sod} A, \operatorname{top} A$, ompB-1, ompC and ompF-1 (Freundlich et al., 1992). The position of the IHF sites at these repressed promoters mostly overlap the RNA-polymerase-binding site $(\operatorname{sod} A,-45 ; \operatorname{top} A,-39 ; \operatorname{omp} B-1,+8)$ although some IHF sites are found far upstream of the RNApolymerase-binding site (ompC, -176; ompF-1; $-179)$. The $n d h$ promoter falls into the former category and repression results from blocking RNA polymerase progress (IHF I, + 26) and competition between RNA polymerase $(-10,-35$ elements) and IHF (IHF II site, -17) for overlapping binding sites. The third IHF binding site (IHF III, -58 ) overlaps the region occupied by RNA polymerase but may also have a role in attenuating Arr-mediated activation of $n d h$ expression.

Repeated attempts to isolate pure samples of Arr which retain the ability to retard $n d h$ DNA have proved unsuccessful. The isolation of glyceraldehyde-3-phosphate dehydrogenase after incubating Arr-containing heparin agarose fractions with $n d h$ promoter DNA attached to Dynabeads is intriguing because glyceraldehyde-3-phosphate dehydrogenase has been shown to interact with both RNA (Singh \& Green, 1993) and single-stranded DNA (Perucho et al., 1980) and now apparently with the double-stranded DNA of the $n d h$ 
promoter. However, as Arr activity was detected in a gap mutant it appears that glyceraldehyde-3-phosphate dehydrogenase is not Arr.

Nevertheless, partially purified samples of Arr were used to detect putative Arr-binding sites. The $n d b$ promoter contains two regions overlapping the $5^{\prime}$ ends of the two FNR sites, which were protected by Arrcontaining fractions (Fig. 1). The Arr II site (-111) overlaps the FNR II site (-94.5) and the Arr I site (-59) overlaps both the FNR I $(-50.5)$ and the IHF III $(-58)$ sites. Thus, under some anaerobic growth conditions Arr may compete with FNR and IHF for occupation of the $n d h$ promoter and, by acting positively, Arr may counteract the negative effects of FNR and IHF to 'finetune' $n d h$ expression. Site-directed mutagenesis of the Arr I site indicates that competition for binding sites at the $n d h$ promoter may occur, although because mutations in the putative Arr I site necessarily result in mutations in the binding sites of other regulators, the results should be treated cautiously. Another possible Arr candidate is the amino-acid-responsive regulator Lrp (Leucine-responsive regulatory protein); however, the putative Arr-binding site sequences do not closely resemble the $\mathrm{Lrp}$ consensus, c/tAG-Aa/tATTa/tT$\mathrm{CTa} / \mathrm{g}$ (Cui et al., 1995) and Lrp has a subunit molecular mass of $18.8 \mathrm{kDa}$, which is much less than the $35 \mathrm{kDa}$ polypeptide originally designated for Arr (Green \& Guest, 1994).

The regulatory response to nutrient quality mediated by Arr is likely to be of general significance, and this was confirmed by the observed interaction between Arrcontaining fraction and ansB DNA. The ans $B$ gene encodes the anaerobic asparaginase II of $E$. coli and requires FNR and anaerobic growth with 17 amino acids for maximum expression (Jennings \& Beacham, 1993; Cedar \& Schwartz, 1968). Arr may thus be responsible for the amino acid responsiveness of ans $B$ expression. Inspection of the ans $B$ promoter reveals a potential Arr site $\left({ }^{-113}\right.$ CCTCTAACTTTGTAG $\left.{ }^{-99}\right)$ centred at -83 relative to transcription start point 2 (Jennings \& Beacham, 1993). Adding this site to the two $n d h$ Arr sites allows a tentative consensus sequence, based on $\geqslant 2$ identities at each position, to be proposed: CAACAAACTTTGTTT. The position of the Arr site $(-83)$ relative to the FNR site $(-41.5)$ of the ansB promoter suggests that Arr and FNR may co-regulate anaerobic ans $B$ expression in a manner analogous to the co-activation of this promoter by tandemly bound FNR and cAMP receptor protein (CRP) (Scott et al., 1995). Arr positioned at -83 would be on the same face of the DNA helix as FNR at -41.5 and thus both regulators could contact RNA polymerase to activate transcription synergistically. This contrasts with the $n d h$ promoter where it is envisaged that Arr and FNR act antagonistically. Further characterization of the interactions between Arr and the $n d h$ and $a n s B$ promoters, and the identification of any necessary co-effector(s) will probably require pure Arr protein. Indeed, the apparent lability of Arr activity could be due to the loss of a coeffector during purification.
The HU protein of $E$. coli is the major protein involved in the organization of the nucleoid. It binds nonspecifically to DNA and although it promotes DNA bending it prefers to interact with DNA that is already bent or kinked such as dA-rich tracts. The role of $\mathrm{HU}$ is to constrain supercoiling by DNA wrapping around several HU dimers. However, $\mathrm{HU}$ has been shown to facilitate the binding of CRP and the lac repressor to the lac promoter, probably by inducing structural transitions (bending and kinking) in the regulator target sequences (Flashner \& Gralla, 1988). Whether HU plays a significant part in the regulation of $n d b$ expression is not yet known but it certainly has a greater affinity for the $n d h$ promoter than for the ans $B$ promoter. It has been shown previously that the FNR site centred at -94.5 is important for efficient FNR-mediated repression of $n d b$ (Green \& Guest, 1994). This site (TTGAT----CCCGG) only matches the consensus sequence in one half-site and it is tempting to speculate that HU may improve FNR-binding at this site.

The strategy for identifying, isolating and defining the role of the individual regulators in order to understand the contribution of each in tuning the expression of the $n d h$ gene of $E$. coli has revealed a complex growth-phase response. Fis represses $n d h$ expression during the transition to exponential growth but may also activate expression when Fis levels are low (Green et al., 1996). In contrast, IHF represses $n d b$ during the later stages of the growth cycle. However, in both cases repression is due to competition between the regulator and RNA polymerase for overlapping binding sites. This appears to be a recurring theme in the regulation of this promoter since the positively acting Arr and the negatively acting FNR also compete for overlapping sites.

The expression of both NADH dehydrogenases of $E$. coli is regulated in response to oxygen availability and to nutrient quality. However, different regulators are used in each case: $n u o A-N$ uses the ArcBA sensor-regulator system for anaerobic regulation whereas $n d h$ uses FNR; nuo $A-N$ responds to $\mathrm{C}_{4}$-dicarboxylic acids whereas $n d b$ responds to amino acids, although it is conceivable that the $\mathrm{C}_{4}$ and amino acid responses are mediated by the same or related regulators. However, both are regulated by IHF, which acts as an anaerobic repressor of both $n u o A-N$ and $n d h$ to provide a degree of co-ordinated expression. The $n d b$ promoter is proving to be an interesting example of a bacterial promoter that responds to several external stimuli via a range of transcription regulators; there is still more to learn about the way these regulators interact, with one another and with RNA polymerase.

\section{ACKNOWLEDGEMENTS}

We are grateful to the following for their generosity in providing some of the strains, plasmids and proteins used in this work: Dr I. R. Beacham (Griffith University, Australia); Dr S. Boschi (CNRS, Nancy, France); Professor S. J. W. Busby (University of Birmingham, UK); Dr R. P. Gunsalus (University of California, Los Angeles, CA, USA); Professor 
C. F. Higgins (University of Oxford, UK); Professor A. Ishihama (National Institute of Genetics, Mishima, Japan); Dr R. C. Johnson (UCLA School of Medicine, LA, USA); and Professor H. Nash (National Institute of Mental Health, Bethesda, USA). We also thank Dr A. J. Moir for amino acid sequencing and Miss M. L. Baldwin for technical assistance. This work was supported by the BBSRC and the Royal Society (J.G.) and The Wellcome Trust (J.R.G).

\section{REFERENCES}

Aviv, M., Giladi, H., Schreiber, G., Oppenheim, A. B. \& Glaser, G. (1994). Expression of the genes coding for the Escherichia coli integration host factor are controlled by growth phase, rpoS, ppGpp and autoregulation. Mol Microbiol 14, 1021-1031.

Ball, C. A., Osuna, R., Ferguson, K. C. \& Johnson, R. C. (1992). Dramatic changes in Fis levels upon nutrient upshift in Escherichia coli. J Bacteriol 174, 8043-8056.

Bongaerts, J., Zoske, S., Weidner, U. \& Unden, G. (1995). Transcriptional regulation of the proton translocating $\mathrm{NADH}$ dehydrogenase genes (nuoA-N) of Escherichia coli by electron acceptors, electron donors and gene regulators. Mol Microbiol 16, 521-534.

Bradford, M. M. (1976). A rapid and sensitive method for the quantitation of microgram quantities of protein utilizing the principle of protein-dye binding. Anal Biochem 72, 248-254.

Calhoun, M. W. \& Gennis, R. B. (1993). Demonstration of separate genetic loci encoding distinct membrane bound respiratory $\mathrm{NADH}$ dehydrogenases in Escherichia coli. J Bacteriol 175, 3013-3019.

Calhoun, M. W., Oden, K. L., Gennis, R. B., Teixeira de Mattos, M. J. \& Neijssel, O. M. (1993). Energetic efficiency of Escherichia coli: effects of mutations in components of the aerobic respiratory chain. J Bacteriol 175, 3020-3025.

Cedar, H. \& Schwartz, J. H. (1968). Production of L-asparaginase II by Escherichia coli. J Bacteriol 96, 2043-2048.

Charpentier, B. \& Branlant, C. (1994). The Escherichia coli gapA gene is transcribed by the vegetative RNA polymerase holoenzyme $\mathrm{E}^{70}$ and by the heat shock RNA polymerase $\mathrm{E} \sigma^{32}$. $J$ Bacteriol 176, 830-839.

Compan, I. \& Touati, D. (1994). Anaerobic activation of $\operatorname{arcA}$ transcription in Escherichia coli: roles of Fnr and ArcA. Mol Microbiol 11, 955-964.

Craig, N. \& Nash, H. (1984). E. coli integration host factor binds to specific sites in DNA. Cell 39, 707-716.

Cui, Y., Wang, Q., Stormo, G. D. \& Calvo, J. M. (1995). A consensus sequence for binding of Lrp to DNA. J Bacteriol 177, 4872-4880.

Ditto, M. D., Roberts, D. \& Weisberg, R. A. (1994). Growth phase variation of integration host factor level in Escherichia coli. $J$ Bacteriol 176, 3738-3748.

Flashner, Y. \& Gralla, J. D. (1988). DNA dynamic flexibility and protein recognition: differential stimulation by bacterial histonelike protein HU. Cell 54, 713-721.

Freundlich, M., Ramani, N., Mathew, E., Sirko, A. \& Tsui, P. (1992). The role of integration host factor in gene expression in Escherichia coli. Mol Microbiol 6, 2557-2563.

Goosen, N. \& van de Putte, P. (1995). The regulation of transcription initiation by integration host factor. Mol Microbiol $16,1-7$.

Green, J. \& Guest, J. R. (1994). Regulation of transcription at the $n d h$ promoter of Escherichia coli by FNR and novel factors. Mol Microbiol 12, 433-444.
Green, J., Anjum, M. F. \& Guest, J. R. (1996). The $n d h$ binding protein (Nbp) regulates the $n d h$ gene of Escherichia coli in response to growth phase and is identical to Fis. Mol Microbiol 20, 1043-1055.

Guest, J. R., Green, J., Irvine, A. S. \& Spiro, S. (1996). The FNR modulon and FNR-regulated gene expression. In Regulation of Gene Expression in Escherichia coli, pp. 317-342. Edited by E. C. C. Lin \& A. S. Lynch. Austin, TX: R. G. Landes Company.

Hayashi, M., Miyoshi, T., Takashina, S. \& Unemoto, T. (1989). Purification of NADH-ferricyanide dehydrogenase and NADHquinone reductase from Escherichia coli membranes and their roles in the respiratory chain. Biochim Biophys Acta 977, 62-69.

Huang, L., Tsui, P. \& Freundlich, M. (1990). Integration host factor is a negative effector of in vivo and in vitro expression of ompC in Escherichia coli. J Bacteriol 172, 5293-5298.

Jennings, M. P. \& Beacham, I. R. (1993). Co-dependent positive regulation of the ansB promoter of Escherichia coli by CRP and the FNR protein - a molecular analysis. Mol Microbiol 9, 155-164.

Johnson, R. C., Ball, C. A., Pfeffer, D. \& Simon, M. I. (1988). Isolation of the gene encoding the Hin recombinatorial enhancer binding protein. Proc Natl Acad Sci USA 85, 3484-3488.

Matsushita, K., Ohnishi, T. \& Kaback, H. R. (1987). NADHubiquinone oxidoreductases of the Escherichia coli aerobic respiratory chain. Biochemistry 26, 7732-7737.

Miller, J. H. (1972). Experiments in Molecular Genetics. Cold Spring Harbor, NY: Cold Spring Harbor Laboratory.

Neijssel, O. M. \& de Mattos, M. J. T. (1994). The energetics of bacterial growth: a reassessment. Mol Microbiol 13, 179-182.

Oppenheim, A. B., Rudd, K. E., Mendelson, I. \& Teff, D. (1993). Integration host factor binds to a unique class of complex repetitive extragenic DNA sequences in Escherichia coli. Mol Microbiol 10, 113-122.

Park, S.-J., Tseng, C.-P. \& Gunsalus, R. P. (1995). Regulation of succinate dehydrogenase ( $s d b C D A B$ ) operon expression in Escherichia coli in response to carbon supply and anaerobiosis: role of ArcA and Fnr. Mol Microbiol 15, 473-482.

Perucho, M., Salas, J. \& Salas, M. (1980). Study of the interaction of glyceraldehyde-3-phosphate dehydrogenase with DNA. Biochim Biopbys Acta 606, 181-195.

Resnik, E., Pan, B., Ramani, N., Freundlich, M. \& Laporte, D. C. (1996). Integration host factor amplifies the induction of the aceBAK operon of Escherichia coli by relieving IcIR repression. $J$ Bacteriol 178, 2715-2717.

Sambrook, J., Fritsch, E. F. \& Maniatis, T. (1989). Molecular Cloning: a Laboratory Manual, 2nd edn. Cold Spring Harbor, NY: Cold Spring Harbor Laboratory.

Sawers, G. (1993). Specific transcriptional requirements for positive regulation of the anaerobically inducible $p f l$ operon by ArcA and FNR. Mol Microbiol 10, 737-747.

Schroder, I., Darie, S. \& Gunsalus, R. P. (1993). Activation of the Escherichia coli nitrate reductase (narGHJI) operon by NarL and Fnr requires integration host factor. $J$ Biol Chem 268, 771-774.

Scott, S., Busby, S. \& Beacham, I. (1995). Transcriptional coactivation at the ans $B$ promoters: involvement of the activating regions of CRP and FNR when bound in tandem. Mol Microbiol 18, 521-531.

Sharrocks, A. D., Green, J. \& Guest, J. R. (1991). FNR activates and represses transcription in vitro. Proc R Soc Lond Ser B Biol Sci 245, 219-226.

Singh, R. \& Green, M. R. (1993). Sequence-specific binding of 
transfer RNA by glyceraldehyde-3-phosphate dehydrogenase. Science 259, 365-368.

Spiro, S., Roberts, R. E. \& Guest, J. R. (1989). FNR-dependent repression of the $n d h$ gene of Escherichia coli and metal ion requirement for FNR regulated gene expression. Mol Microbiol 3, 601-608.

Tran, Q. H., Bongaerts, J., Vlad, D. \& Unden, G. (1997). Requirement for the proton-pumping NADH dehydrogenase I of Escherichia coli in respiration of $\mathrm{NADH}$ to fumarate and its bioenergetic implications. Eur J Biochem 244, 155-160.
Weidner, U., Nehls, U., Schneider, R. \& 8 other authors (1992) Molecular genetic studies of complex I in Neurospora crassa, Aspergillus niger and Escherichia coli. Biochim Biophys Acta 1101, 177-180.

Young, I. G., Rogers, B. L., Campbell, H. D., Jaworowski, A. \& Shaw, D. D. (1981). Nucleotide sequence for the respiratory NADH dehydrogenase of Escherichia coli. Eur J Biochem 116 , 165-170.

Received 16 May 1997; accepted 2 June 1997. 